- ACORN Australan college of | JOURNAL OF PERIOPERATIVE NURSING

\title{
Ex utero intrapartum treatment (EXIT) procedure: Indications and procedural considerations
}

Follow this and additional works at: https://www.journal.acorn.org.au/jpn

Part of the Health Services Administration Commons, Health Services Research Commons, Perioperative, Operating Room and Surgical Nursing Commons, and the Surgery Commons

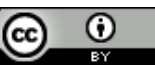

This work is licensed under a Creative Commons Attribution 4.0 License.

\section{Recommended Citation}

Silva, Melissa (2019) "Ex utero intrapartum treatment (EXIT) procedure: Indications and procedural considerations," Journal of Perioperative Nursing: Vol. 32 : Iss. 4 , Article 2.

Available at: https://doi.org/10.26550/2209-1092.1068

https://www.journal.acorn.org.au/jpn/vol32/iss4/2

This Article is brought to you for free and open access by Journal of Perioperative Nursing. It has been accepted for inclusion in Journal of Perioperative Nursing by an authorized editor of Journal of Perioperative Nursing. 
Guest Editor

Paula Foran

PhD, MACN, FACORN

Author

Melissa Silva

RN, MCN

\title{
Ex utero intrapartum treatment (EXIT) procedure: Indications and procedural considerations
}

\author{
Abstract \\ Problem identification \\ Ex Utero Intrapartum Treatment (EXIT) has become the optimal delivery \\ strategy in fetuses with airway compromise; however, it remains an extremely \\ rare procedure. This review aims to provide perioperative nurses with an \\ overview of EXIT procedure to enable them to be an effective member of the \\ multidisciplinary team.
}

\section{Literature search}

An electronic search of the CINAHL, Medline and Scopus databases was undertaken yielding 19 articles for inclusion in this integrative review. The papers included were case studies, case series or retrospectives and describe 42 EXIT procedures with 43 babies.

\section{Data evaluation synthesis}

The most common indication for the EXIT procedure is neck tumours, with other indications being congenital high airway obstruction syndrome (CHAOS), cardiac anomalies, extremely low birth weight (ELBW), micrognathia and congenital diaphragmatic hernia. Literature revealed 41 cases had successful establishment of an airway, with the procedure failing in two cases, both with diagnoses of CHAOS.

\section{Implications for perioperative nursing practice or research}

The role of the perioperative nurse within these cases needs to be explored further. Perioperative nurses need to have the skills and ability to participate as key members of the multidisciplinary team. This can be achieved through in-depth understanding of the topics within this review.

Keywords: EXIT procedure, ex utero intrapartum treatment, cervical teratoma, congenital high airway obstruction syndrome (CHAOS)

\section{Introduction}

Ex utero intrapartum treatment (EXIT) procedure is performed when there is airway compromise in the fetus ${ }^{1}$. Braden et al. ${ }^{2}$ describe it as a modified caesarean birth, where the fetus is partially delivered in order to secure the airway or commence extra corporeal membrane oxygenation (ECMO) while oxygenation to the fetus is maintained via uteroplacental circulation. Resection of the mass and separation of conjoined twins may also occur during EXIT procedure; however, these are rare ${ }^{3}$. Duek et al. ${ }^{4}$ explain EXIT procedure has the ability to turn a potentially catastrophic situation into a controlled elective scenario.

EXIT procedure was first described in the 1990s for reversal of tracheal occlusion in fetuses with congenital diaphragmatic hernia ${ }^{5}$. Since that time, there has been a significant 
increase in the indications for the procedure, with Gonzales et al. ${ }^{6}$ recognising EXIT is now considered for neck mass, congenital high airway obstruction syndrome (CHAOS), micrognathia, mediastinal or pericardial tumours, and any pathologic condition where airway compromise is suspected.

Kornacki et al. ' identified the three most important aspects of EXIT as being:

1. specific fetal anaesthesia and anaesthesia to ensure the uterus remains relaxed with placental perfusion

2. careful hysterotomy to prevent haemorrhage

3. fetal airway securement in accordance with an airway algorithm.

Success of the procedure is dependent on accurate diagnosis prior to the procedure, a multidisciplinary approach, and appropriate facilities to carry out the procedure 4 .

The data evaluation and synthesis of literature in this review will first discuss literature on the EXIT procedure, followed by indications for EXIT surgical intervention, implications for perioperative nurses, and finally describe knowledge translation for this rare surgical procedure.

\section{Problem identification}

EXIT has become the optimal delivery strategy in fetuses with airway compromise $^{8}$. Despite this, the procedure remains extremely rare, highlighted by a retrospective study by Brodsky et al. ${ }^{9}$ who identified only four EXIT procedures for cervical teratoma being carried out in their facility in a 41-year period. There are many case studies in the literature; however, few papers provide comprehensive literature reviews. This integrative review was undertaken with the intention of providing perioperative nurses with an understanding of EXIT procedure.

\section{Literature search}

\section{Design}

This review follows the stages of an integrative review as described by Whittemore and Knafl ${ }^{10}$. The integrative review adds to the evidence base of nursing through inclusion of a variety of source material and thus provides a diverse view of the phenomenon being explored. Whittemore and Knafl ${ }^{10}$ explain this type of review has five stages - problem identification, literature searches, data evaluation, data integration and results presentation. By following these stages, a comprehensive review of the literature has been undertaken.

\section{Literature search methods}

An electronic search of the literature was undertaken using the University of Tasmania's database search function. The Scopus, Cumulative Index to Nursing and Allied Health Literature (CINAHL) and Medline databases were all searched using the terms 'EXIT procedure' or 'ex utero intrapartum treatment'. Due to an extensive number of articles identified, results were limited to articles published after January 2016. Additional inclusion criteria limited the results to academic papers that were written in English, with full text availability and focused on EXIT procedure. Articles were excluded if they focused on the indication rather than the procedure, or were editorials or poster presentations. The titles and abstracts of 139 articles were read to identify relevance to the inclusion and exclusion criteria. The majority of the final 19 articles chosen were case studies and case series with two retrospective analyses. Reference lists of the reviewed articles were examined to identify any additional relevant articles.

\section{Data analysis}

Articles were read and reread by the author with a summary of the findings in Table 1. The articles sourced were all case studies, case series or retrospectives providing insights into the cases ranging from detailed accounts to broad overviews. The indications for the procedure and fetal outcomes were identified. Findings were grouped initially in accordance with the indication for EXIT procedure with further implications identified as subthemes. Anaesthetic and surgical considerations were compared and are summarised in the data evaluation synthesis.

\section{Data evaluation synthesis}

The majority of papers discussed in this review are case studies, an understandable finding due to the nature of the procedure and its rarity. The 19 papers describe 42 EXIT procedures with 43 babies (including one set of twins). Despite the reports coming from several countries including USA (nine), Israel (two), Poland (two), Japan (one), Korea (two), India (one), Taiwan (one) and Spain (one), the anaesthetic and surgical considerations for the cases were all remarkably similar. 


\begin{tabular}{|c|c|c|c|}
\hline $\begin{array}{l}\text { Author, year, } \\
\text { country }\end{array}$ & Type of article & Indication for EXIT & EXIT and fetal outcomes \\
\hline $\begin{array}{l}\text { Hochwald et al. } \\
\text { 2019, Israel }\end{array}$ & Case report & $\begin{array}{l}\text { Cervical teratoma, } \\
\text { polyhydramnios }\end{array}$ & $\begin{array}{l}\text { Airway secured via rigid bronchoscopy. } \\
\text { Mass resected. }\end{array}$ \\
\hline $\begin{array}{l}\text { Kornacki et al. 2019, } \\
\text { Poland }\end{array}$ & Four case reports & $\begin{array}{l}\text { Three neck tumours (goitrous } \\
\text { hypothyroidism, cystic } \\
\text { lymphatic malformation, giant } \\
\text { teratoma), one CHAOS }\end{array}$ & $\begin{array}{l}\text { Three neck tumours had successful intubations. } \\
\text { CHAOS unable to be intubated. }\end{array}$ \\
\hline $\begin{array}{l}\text { Said et al. 2019, } \\
\text { USA }\end{array}$ & Case report & $\begin{array}{l}\text { Hypoplastic left heart } \\
\text { syndrome }\end{array}$ & $\begin{array}{l}\text { Septectomy performed twice due to inadequate decompression, } \\
\text { airway secured with rigid bronchoscope: normal structures noted. } \\
\text { Day } 9 \text { infant suffered intraventricular haemorrhage and died (DNR } \\
\text { had been established). }\end{array}$ \\
\hline $\begin{array}{l}\text { Shamshirsaz et al. } \\
\text { 2019, USA }\end{array}$ & $\begin{array}{l}\text { Retrospective study of ten } \\
\text { cases }\end{array}$ & $\begin{array}{l}\text { Cervical lymphatic } \\
\text { malformations }\end{array}$ & $\begin{array}{l}\text { Airway secured in all cases. } \\
\text { One death (day 8). } \\
\text { Three discharged with tracheostomy. } \\
\text { Six other cases assumed well. }\end{array}$ \\
\hline $\begin{array}{l}\text { Agarwal et al. 2018, } \\
\text { USA }\end{array}$ & $\begin{array}{l}\text { Case report and literature } \\
\text { review }\end{array}$ & $\begin{array}{l}\text { Fetal mediastinal teratoma } \\
\text { with non-immune fetal } \\
\text { hydrops }\end{array}$ & EXIT-to-resection of tumour. \\
\hline $\begin{array}{l}\text { Asai et al. 2018, } \\
\text { Japan }\end{array}$ & Case report & $\begin{array}{l}\text { Collet Edwards type II with } \\
\text { truncal valve stenosis }\end{array}$ & $\begin{array}{l}\text { EXIT-to-ECMO } \\
\text { Transferred to another operating room for cardiac procedure. } \\
\text { Infant died day } 24 \text { due to multi-organ failure from infection. }\end{array}$ \\
\hline $\begin{array}{l}\text { Duek et al. 2018, } \\
\text { Israel }\end{array}$ & Case report & $\begin{array}{l}\text { Pierre Robin with severe } \\
\text { micrognathia and cleft palate }\end{array}$ & $\begin{array}{l}\text { Modified EXIT due to breech presentation. } \\
\text { Tracheostomy secured. }\end{array}$ \\
\hline $\begin{array}{l}\text { Gonzales et al. 2018, } \\
\text { USA }\end{array}$ & Case report & CHAOS: tracheal atresia & $\begin{array}{l}\text { Tracheostomy. } \\
\text { Tracheal slide procedure. }\end{array}$ \\
\hline $\begin{array}{l}\text { Lee et al. 2018, } \\
\text { Korea }\end{array}$ & Two case reports & $\begin{array}{l}\text { Cervical lymphangioma } \\
\text { CHAOS }\end{array}$ & $\begin{array}{l}\text { Case one intubated at } 12 \text { minutes. } \\
\text { Case two tracheostomy at ten minutes. }\end{array}$ \\
\hline $\begin{array}{l}\text { Subramanian et al. } \\
2018 \text {, India }\end{array}$ & $\begin{array}{l}\text { Case report and literature } \\
\text { review }\end{array}$ & Teratoma & $\begin{array}{l}\text { Plan } \mathrm{C} \text { tracheostomy attempted but failed, additional attempt at } \\
\text { oral intubation successful. } \\
\text { Aspiration and infection at two months caused fetal death. }\end{array}$ \\
\hline $\begin{array}{l}\text { Pucher et al. 2018, } \\
\text { Poland }\end{array}$ & $\begin{array}{l}\text { Case series of seven cases } \\
\text { and report }\end{array}$ & $\begin{array}{l}\mathrm{CDH}, \mathrm{CHAOS} \text {, fetal neck } \\
\text { masses (two teratoma, two } \\
\text { lymphatic malformation, } \\
\text { infantile haemangioma) }\end{array}$ & $\begin{array}{l}\text { CDH: baby died day two. } \\
\text { CHAOS: unable to establish airway, baby died shortly after } \\
\text { procedure. } \\
\text { Neck masses: all successfully intubated. }\end{array}$ \\
\hline $\begin{array}{l}\text { Olivares et al. 2018, } \\
\text { USA }\end{array}$ & Case report & Cervical teratoma & $\begin{array}{l}\text { Tracheostomy. } \\
\text { Infant died at six weeks. }\end{array}$ \\
\hline $\begin{array}{l}\text { Hung et al. 2017, } \\
\text { Taiwan }\end{array}$ & $\begin{array}{l}\text { Two case reports (twins and } \\
\text { single fetus) }\end{array}$ & Extremely low birth weight & All three intubated. \\
\hline $\begin{array}{l}\text { Cuneo et al. 2017, } \\
\text { USA }\end{array}$ & Case report & Complete atrioventrical block & Intubated, EXIT to pacing successful. \\
\hline $\begin{array}{l}\text { Braden et al. 2016, } \\
\text { USA }\end{array}$ & Case report & $\begin{array}{l}\text { Micrognathia and } \\
\text { retrognathia }\end{array}$ & Endotracheal tube placed with rigid bronchoscope. \\
\hline $\begin{array}{l}\text { Brodsky et al. 2017, } \\
\text { USA }\end{array}$ & $\begin{array}{l}\text { Retrospective: } 14 \text { teratoma } \\
\text { cases, four delivered via EXIT }\end{array}$ & Four teratoma & $\begin{array}{l}\text { Three intubations. } \\
\text { One tracheostomy. }\end{array}$ \\
\hline $\begin{array}{l}\text { Byun et al. 2016, } \\
\text { Korea }\end{array}$ & Case report & $\begin{array}{l}\text { Giant cyst of fourth branchial } \\
\text { cleft }\end{array}$ & Intubated by Glidescope in five minutes. \\
\hline $\begin{array}{l}\text { Matte et al., 2016, } \\
\text { USA }\end{array}$ & Case report & $\begin{array}{l}\text { Cervical teratoma extending } \\
\text { into right chest }\end{array}$ & $\begin{array}{l}\text { EXIT-to-ECMO. } \\
\text { Baby then transferred to another operating room where } \\
\text { tracheotomy performed, suction catheter inserted up to mouth } \\
\text { then endotracheal tube threaded over catheter and patient } \\
\text { intubated. }\end{array}$ \\
\hline $\begin{array}{l}\text { Rodriguez et al. } \\
\text { 2016, Spain }\end{array}$ & Case report & Cervical teratoma & $\begin{array}{l}\text { Mass aspirated ( } 270 \mathrm{ml} \text { yellowish fluid) allowed space for } \\
\text { intubation. }\end{array}$ \\
\hline
\end{tabular}




\section{The procedure}

Preparation for EXIT procedure is extremely important to optimise the outcomes for the fetus and reduce risks to both mother and baby ${ }^{6}$. Most authors recognise the necessity of a multidisciplinary team being engaged early to discuss the potential for EXIT procedure ${ }^{1-6,9,11-15,17,19,20}$. This team would consist of neonatologist, maternalfetal medicine expert, obstetrician, anaesthetist, paediatric surgeon, paediatric otolaryngologist, radiologist, midwives and nurses $2,3,4,11$. Simulation of the procedure is an important step, with all possible outcomes discussed and anticipated ${ }^{8,11}$. Gonzales et al. ${ }^{6}$ recommended a 'dry-run' covering the room setup, availability of essential equipment and potential adverse events, with the attendance of at least one representative from each team including mandatory attendance of instrument, circulating and anaesthesia nurses. A possible room setup adapted from
Subramanian et al.12 is included as Figure 1.

Brodsky et al. ${ }^{9}$ identified that appropriate imaging can aid in determining the airway management plan and surgical approach.

Kornacki et al.? recommended the use of ultrasound and fetal magnetic resonance imaging (MRI) to appropriately diagnose the extent of airway obstruction. Lee et al. ${ }^{13}$ added that although both methods are acceptable, fetal MRI is superior, recognising that the absence of this in one of their cases may have extended intubation time. Alternatively, Brodsky et al. ${ }^{9}$ highlighted the usefulness of ultrasound at distinguishing between masses such as teratomas and lymphatic malformations. Fetal and placental position must also be assessed prior to commencement of the procedure. Breech position may require a modified EXIT as performed by Duek et al. ${ }^{4}$, or external cephalic version and anterior placental position may require an upper segment uterine incision ${ }^{14}$.

Rodriguez et al. ${ }^{8}$ explain that EXIT procedure has two patients, the mother and the baby, therefore the needs of both must be considered and both should have a designated anaesthetist. Initially the mother will be the primary focus and her designated anaesthetist will most likely administer a general anaesthetic with rapid sequence induction ${ }^{12}$, and this occurred in all the reviewed cases that reported the type of anaesthesia used. Subramanian et al.12 found that regional anaesthesia has been used; however, this may lead to increased maternal anxiety, and due to the high risk of blood loss, general anaesthetic is more appropriate. Epidural was used in some cases as a form of post-operative pain relief ${ }^{12,15}$.

Figure 1: Operating theatre setup (adapted from Subramanian ${ }^{12}$ )

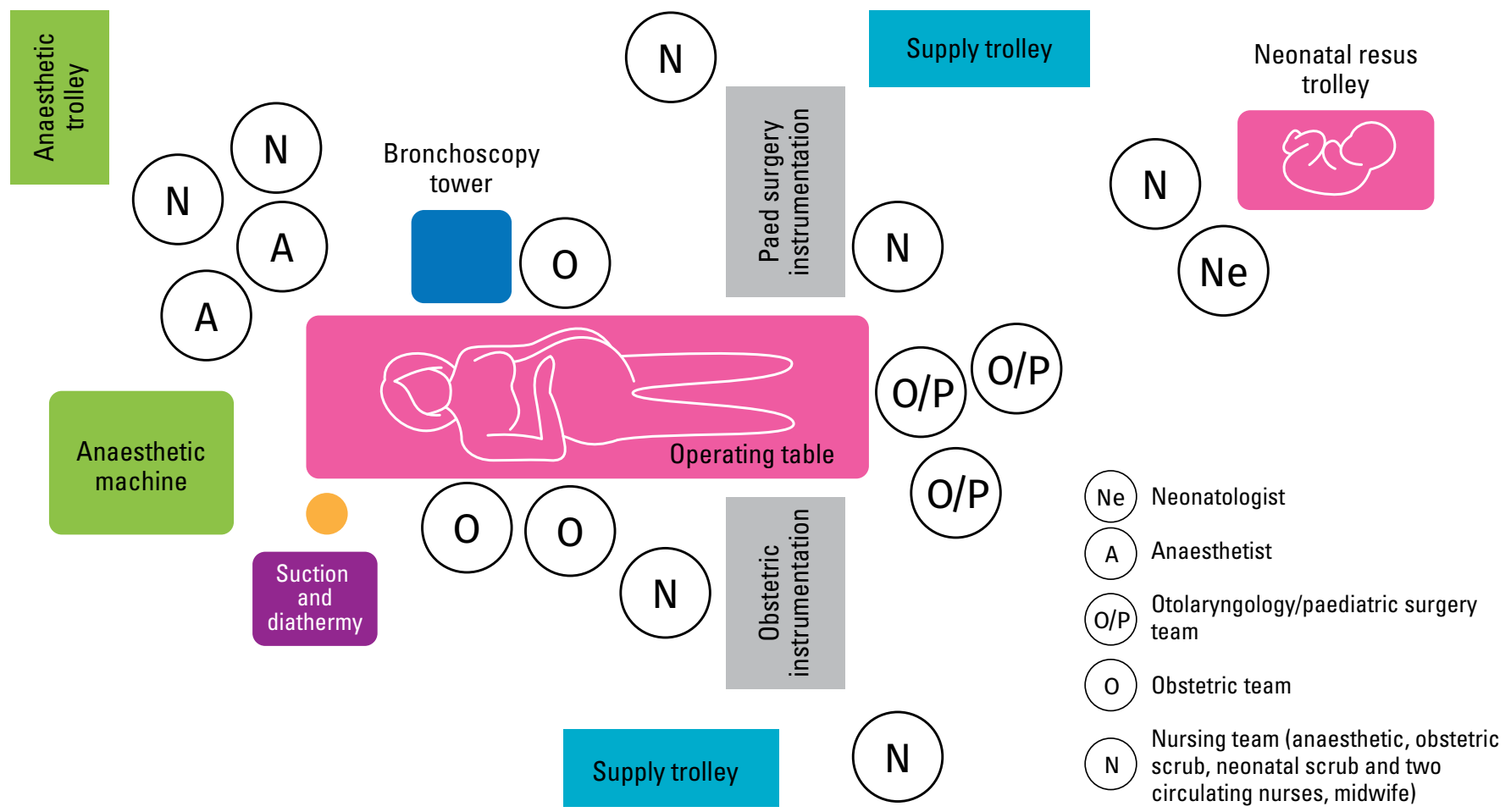


General anaesthetic allows for the use of inhalation agents which cause tocolysis, described by Braden et al. ${ }^{2}$ as complete uterine relaxation. Tocolysis prevents placental separation, therefore is essential for the success of the EXIT procedure and, in turn, survival of the fetus ${ }^{12}$. In addition to inhalational agents such as desflurane ${ }^{2,12}$ sevoflurane and isoflurane ${ }^{15}$, nitroglycerine was reported by multiple authors as being used to maintain tocolysis 2,8,1,12 $^{2}$ Tocolytic agents may cause maternal hypotension, which in turn may interfere with the maintenance of placental circulation and fetal oxygenation ${ }^{8}$. Some authors reported the use of an arterial line $e^{1,2,12}$ to monitor maternal blood pressure, while others had this as standby equipment ${ }^{2}$. Phenylephrine ${ }^{2,8}$ and dopamine ${ }^{1}$ were reported as being used to maintain maternal blood pressure. Cuneo et al. ${ }^{15}$ suggested that inhalational agents may cause bradycardia in the fetus, a potential complication particularly in fetuses with cardiac anomalies, and administered epinephrine and isoproterenol intravenously to counter this.

Following administration of general anaesthesia, the obstetrician will commence the procedure. Ideally, a lower segment uterine incision is used; however, in the case of anterior placenta, such as that described by Shamshirsaz et al.14, an upper segment hysterotomy may be necessary. Prior to uterine incision, the tone should be checked to ensure the uterus is adequately relaxed $^{8}$. Although tocolysis is necessary for the success of the surgery, it increases the risk of severe bleeding $^{12}$. The harmonic scalpel ${ }^{12}$ and staplers ${ }^{6,15}$ have been used to reduce this risk of haemorrhage. Subramanian et al.12 cites one case in which the procedure had to be abandoned due to haemorrhage despite the use of harmonic scalpel; however, this was not an outcome in any of the cases reviewed. Hung et al. ${ }^{16}$ describes the placement of transarterial balloons bilaterally in the patient's internal iliac arteries as a preventative measure for postpartum haemorrhage. This is not described in any other cases and was not required to be used; therefore, may be an unnecessary invasive procedure.

The surgical team must also be aware of maintaining uterine volume and temperature to prevent placental separation and umbilical cord spasm $^{5,13}$. Several authors described the use of an amniotic infusion with either warm Ringer's solution ${ }^{8,15}$ or normal saline ${ }^{13}$ to achieve this. Preservation of amniotic fluid is also maintained through partial delivery of the fetus ${ }^{4}$. The head, one arm and upper body of the fetus only is delivered, with the lower body and umbilical cord remaining in the uterus to preserve heat and amniotic fluid $^{4}$. Fetal monitoring may occur with echocardiography ${ }^{11}$, pulse oximetry ${ }^{13,15}$ or ultrasound heart rate monitoring ${ }^{8}$. Subramanian et al.12 suggest monitoring options include observing colour, cord pulsations, precordial stethoscope, fetal scalp electrodes, umbilical cord blood gases and transoesophageal echocardiography. There are some reports of muscle relaxants and opioids being administered directly to the fetus via intravenous, umbilical or intramuscular routes to ensure the fetus remains adequately anaesthetised for the procedure $\mathrm{e}^{6,8,17}$. With fetal anaesthesia confirmed, the neonatologist, anaesthetist or ENT surgeon commence assessment of the airway.

Subramanian et al.12 explained that there must be backup plans in place and recommended using an airway

Figure 2: Fetal airway algorithm (Subramanian et $\mathrm{al}^{12}$ )

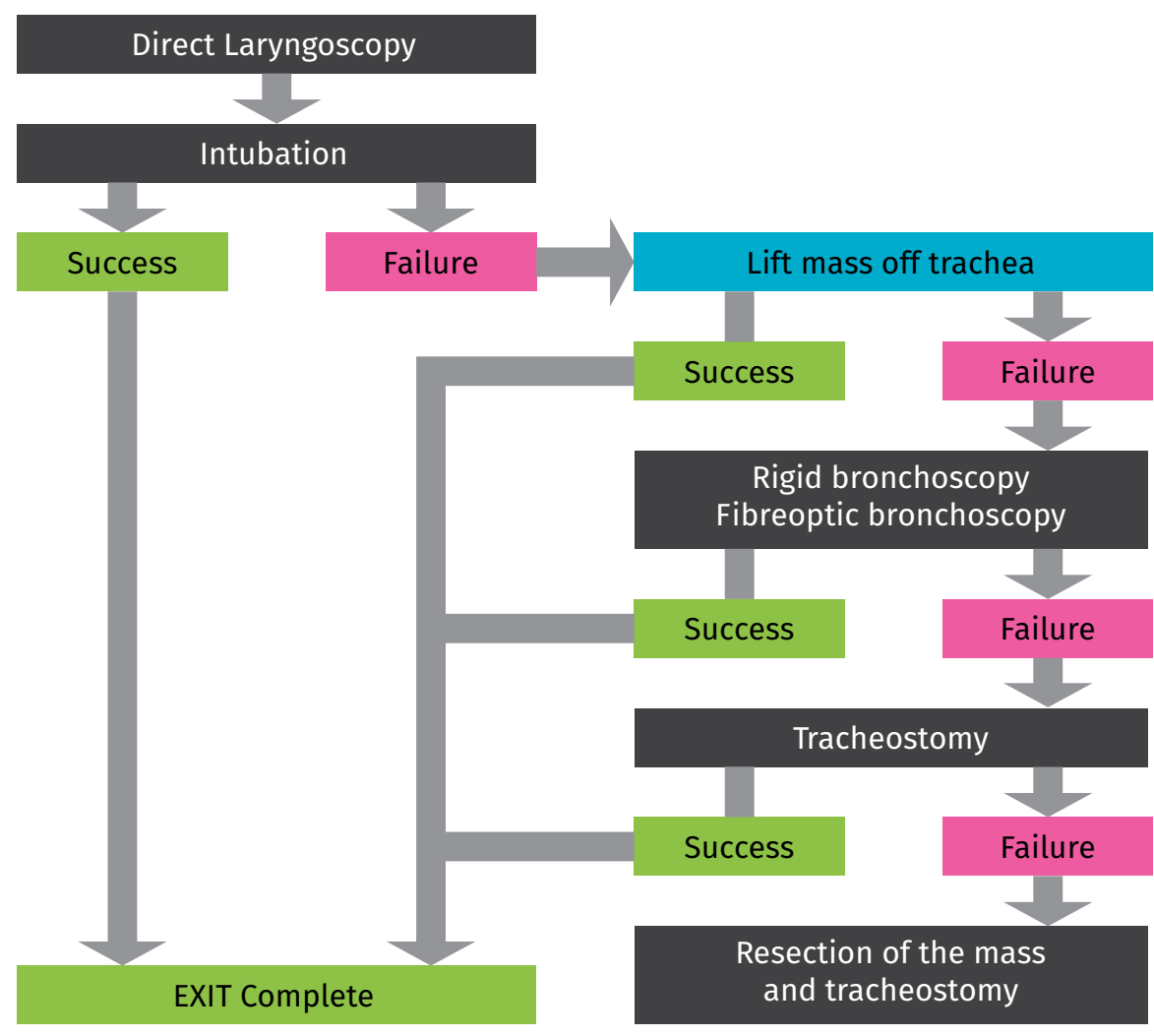


algorithm (Figure 2) similar to that described by Pucher et al. ${ }^{3}$. The algorithm provided is specific to neck mass; however, it may be adapted for other indications. Direct laryngoscopy or the use of glidescope video laryngoscope ${ }^{1}$ was the first step in the majority of cases, followed by rigid or fibreoptic bronchoscopy and, if these fail, tracheostomy. Byun et al. explained the glidescope video laryngoscope is useful in neonates as it has a 60-degree angulated blade and digital camera and they successfully used this. Alternatively, Braden et al. ${ }^{2}$ were unable to visualise the glottic opening with the glidescope. In two of the cases, ECMO commenced due to cardiac abnormalities ${ }^{18}$. One neck mass was noted to be so large it extended into the right chest ${ }^{5}$. Following successful airway or ECMO establishment, which occurred in 41 of the 43 cases identified in this review, the fetus was fully delivered, the cord clamped, and the neonate transferred to neonatal intensive care unit (NICU) or another operating theatre for further treatment.

Oxytocin ${ }^{2}$, carbetocin?, methylergometrine ${ }^{8}$ and sulprostone ${ }^{13}$ are all reported as being used following cord clamping to ensure return of uterine tone, preventing maternal haemorrhage ${ }^{12}$. Despite haemorrhage being reported as a significant risk during EXIT procedure, the majority of cases had blood loss around the average for caesarean section. The exception was Lee et $\mathrm{al}^{13}$, who reported a greater than two litre loss in one of their cases. This was managed conservatively, and the mother had no complications ${ }^{13}$. There are no reports of maternal complications in any of the reviewed cases.

EXIT is a complex procedure requiring full appreciation of the ethics, prognosis and survival rates ${ }^{6}$. Many babies will require long-term tracheostomy and further procedures and treatments ${ }^{12}$. Subsequent care must be maintained to avoid secondary complications such as aspiration and infection ${ }^{12}$.

\section{Indications for EXIT surgical intervention}

The most common indication for the EXIT procedure is neck tumours, accounting for 30 of the 43 cases described. Other indications include congenital high airway obstruction syndrome (CHAOS) (four cases), cardiac anomalies (three cases), extremely low birth weight (three cases), micrognathia (two cases) and congenital diaphragmatic hernia (one case). EXIT procedure was successful in 41 of the cases identified with establishment of an airway or ECMO. In two cases, attempts to secure an airway failed. One of the neonates died during the procedure and one shortly after, both with a diagnosis of CHAOS. Six other deaths occurred in the days or months following the procedure and it is assumed the other 35 survived to the time of reporting

\section{Neck tumours}

Neck tumours may compress or displace the airway, therefore performing an EXIT procedure to secure the airway prior to delivery is the optimal treatment option ${ }^{8}$. Rodriguez et al. ${ }^{8}$ reported that prior to EXIT, neck masses had a mortality rate of up to 40 per cent, and those that did survive had a high morbidity rate. This is supported by Byun et al. who believed that EXIT procedure can reduce the mortality rate of neonates with neck masses to as low as eight per cent.

Neck tumours resulting in EXIT procedures in the articles reviewed were teratomas, lymphatic malformation, haemangioma, goitrous hypothyroidism and a giant cyst of the fourth branchial cleft.

\section{Teratoma}

Teratomas are extremely rare tumours, accounting for one case in every 40000 live births, and have unknown pathophysiology ${ }^{11}$. They most commonly occur in the sacrococcygeal region ${ }^{11}$, with the second most common area being mediastinal ${ }^{19}$ and less than ten per cent occurring in the neck ${ }^{11}$. They contain tissue from the three primordial embryonic layers - mesoderm, ectoderm and endoderm ${ }^{11,20}$ - are highly vascular and grow quickly due to cystic components ${ }^{9}$. Hochwald et al.11 explained that teratomas are histologically benign but have a high morbidity and mortality rate due to their size and location ${ }^{20}$. Teratomas may compress the airway or pull the trachea and lungs superiorly against the thoracic inlet causing pulmonary hypoplasia ${ }^{3}$. Brodsky et al. ${ }^{9}$ added that teratomas may also be fatal as they can cause fetal hydrops (abnormal accumulation of fluid in the fetal compartment) ${ }^{21}$ and premature delivery due to their size. Polyhydramnios (an abnormal increase in the volume of amniotic fluid) 22 may be caused by the teratoma constricting the upper gastrointestinal tract and is also indicative of airway compression ${ }^{11}$. Rodriguez et al. ${ }^{8}$ identified EXIT as the safest delivery option in actual or potentially airway compromised fetuses.

In 13 cases with neck tumour, teratoma was diagnosed -12 of these were cervical and one mediastinal. Cervical teratomas account for approximately three per cent of all teratomas ${ }^{3}$ with Olivares et al. ${ }^{20}$ stating this number could be closer to nine per cent. Cervical teratomas often contain thyroid tissue or may replace part of the gland which has led to speculation that they arise from thyroid tissue ${ }^{9}$. Brodsky et al. ${ }^{9}$ dispute this, as the thyroid is often separated from the tumour by a capsule. 
The 12 cervical teratoma cases all had an airway secured at the time of the procedure. Nine of the cases were able to be intubated with an endotracheal tube either via direct laryngoscopy or rigid bronchoscopy. Rodriguez et al. ${ }^{8}$ explained that in their case the trachea was displaced and initial intubation attempts failed. In this case 270 millilitres of yellowish fluid was aspirated under ultrasound guidance from the mass which provided enough relief to allow intubation ${ }^{8}$. Agarwal et al..$^{19}$ described the use of a rigid bronchoscope to confirm narrowing of the trachea but did not provide specifics on how the infant was intubated. The report refers to lung compliance, therefore it is assumed the patient was intubated via the rigid bronchoscopy. Kornacki et al. ${ }^{7}$ explained the teratoma in their fetus had partially destroyed the left mandible; despite this, intubation was still able to be achieved easily during EXIT.

Two cases had the airway secured via tracheostomy. Olivares et al. ${ }^{20}$ explain this may be necessary when the airway is difficult to access, due to the mass obstructing the upper airway to a degree that oral intubation is not possible?. Brodsky et al. ${ }^{9}$ add that an inability to secure a tracheostomy due to the size or location of the mass rarely occurs; however, if it does, partial resection of the tumour may be necessary. Subramanian et al.12 had difficulty securing a tracheostomy as the trachea was deep and deviated. They had attempted tracheostomy while the infant was still attached to placental circulation; however, the infant was fully delivered and positioned on a mayo stand for the procedure ${ }^{12}$. Additional laryngoscopy attempts revealed bubbles in the glottis and oral intubation was successful.

The final cervical teratoma case is reported by Matte et al. ${ }^{5}$ who explained the teratoma had entered the chest cavity and involved the superior vena cava and right atrium. In order to maintain oxygenation in the fetus, it was decided to undertake EXIT-to-ECMO. EXIT-toECMO is a useful strategy if an airway cannot be established, the fetus and placental support become unstable, or the lungs cannot support the fetus during the neonatal period ${ }^{5}$. In their case, the otolaryngology team was unable to visualise the trachea so a sternotomy was performed and ECMO was commenced within three minutes ${ }^{5}$. The baby was then delivered and transferred to another room where the otolaryngology team performed a tracheotomy, inserted a suction catheter into the trachea and out the mouth, then threaded the ETT over the suction catheter. With the oral airway secured, they then closed the tracheotomy 5 .

There were 12 cases where tumours were resected, all in separate procedures in the days or weeks following the EXIT procedure. The case described by Olivares et al. ${ }^{20}$ did not have a resection, possibly due to the infant requiring high levels of ventilator support in NICU. In their discussion, the authors confirm that resection can only be performed if the patient is stable ${ }^{20}$. The infant died at six weeks four days of age. One other case describes the death of an infant two months after the procedure due to recurrent aspirations and infection ${ }^{12}$. Brodsky et al. ${ }^{9}$ explain that early tumour resection is recommended but that the EXIT procedure should focus on securing an airway, with resection occurring only if this is unable to be achieved.

Agarwal et al.19 described an EXIT procedure performed for mediastinal teratoma, a tumour which may be associated with compression of intrathoracic structures, non-immune fetal hydrops (NIFH) and respiratory distress ${ }^{19}$. Agarwal et al..$^{19}$ explain this is a rare occurrence, with EXIT even rarer, identifying just one reported previous case treated with this procedure. Agarwal et al. ${ }^{19}$ described their patient as having NIFH and a large pericardial effusion and tracheal narrowing compromising mechanical ventilation was confirmed with a rigid bronchoscope. Due to the inability to adequately ventilate the infant, the tumour was resected as part of the EXIT, and the effusion drained.

\section{Lymphatic malformation}

Lymphatic malformations are another type of benign tumour, accounting for one case in every 20000 births $^{14}$ and five per cent of benign tumours in infants ${ }^{3}$. Two thirds of cases are found in the head or neck ${ }^{3}$. Pucher et al. ${ }^{3}$ explain that lymphatic malformations affect the airway slightly differently to teratomas with Shamshirsaz et al. ${ }^{14}$ confirming they tend to cause airway deviation rather than compression as they are softer than teratomas.

Pucher et al. ${ }^{3}$ and Kornacki et al.? both described simple oral intubations for their three cases of lymphatic malformations and all three went on to have successful resections of the mass. Lee et al.13 explained that it took 12 minutes and several attempts to secure an oral airway in their case.

Shamshirsaz et al.14 described ten cases of lymphatic malformation treated with EXIT procedure over an 18-year period. An airway was able to be secured in all ten cases with one case requiring drainage of a cyst prior to delivery ${ }^{14}$. Shamshirsaz et al. ${ }^{14}$ did not disclose the types of airways secured at the time of procedure but went on to explain that three of the infants were discharged home with a tracheostomy. They discovered one death in their retrospective study - the infant had arrested 
during an emergency EXIT procedure, a tracheostomy was performed, and they were transferred to NICU where they died on day eight.

\section{Other neck masses}

Byun et al.' described an EXIT procedure performed due to polyhydramnios caused by a giant cyst of the fourth branchial cleft. The clinicians used a glidescope video laryngoscope due to reports that it would provide a better view than a traditional laryngoscope, and the fetus was intubated in just five minutes ${ }^{1}$. Kornacki et al. described intubation for a fetus with goitrous hypothyroidism as straightforward. Pucher et al. ${ }^{3}$ also stated a fetus with haemangioma in their report was able to be intubated; however, the report did not provide details. The haemangioma was treated conservatively with positive outcomes ${ }^{3}$.

\section{Congenital high airway obstruction syndrome}

Congenital high airway obstruction syndrome (CHAOS) is characterised by lung expansion, inverted diaphragm and non-immune hydrops ${ }^{6}$. These symptoms are caused by fluid trapped in the lungs due to near complete or complete obstruction of the fetal airway ${ }^{6}$. This is most commonly caused by laryngeal atresia but may also be caused by tracheal atresia, subglottic or tracheal stenosis, laryngeal cyst or web ${ }^{3,6}$. Gonzales et al. ${ }^{6}$ state that prior to the development of EXIT procedure, tracheal atresia was uniformly fatal. EXIT has improved the prognosis of these patients though not as significantly as in other indications. Out of the four cases reported in the articles, two survived to one year of age with the other two passing away during or shortly after the procedure.
Lee et al. ${ }^{13}$ reported symptoms of enlarged, hyperechoic, homogeneous lungs with inverted diaphragm, anteriorly displaced heart and polyhydramnios. Laryngoscopy confirmed there was no visible airway; therefore, a tracheostomy was performed. The baby was treated conservatively and discharged with a tracheostomy in situ. Gonzales et al. ${ }^{6}$ described polyhydramnios, skin oedema, ascites, pericardial effusion and ultrasound as signs of tracheal atresia in their fetus. During the procedure, laryngoscopy and bronchoscopy confirmed the diagnosis and a tracheostomy was performed. The baby underwent a slide tracheoplasty and was well at one year old.

Pucher et al. ${ }^{3}$ and Kornacki et al. both described less successful EXIT procedures for CHAOS. Pucher et al. ${ }^{3}$ explained their patient, with a diagnosis of laryngeal atresia, required an emergency EXIT at 27 weeks due to premature rupture of membranes. Tracheostomy was attempted; however, the baby died shortly after the procedure ${ }^{3}$. Kornacki et al.? also presented a case with tracheal atresia with an inability to place a tracheostomy. An autopsy confirmed the diagnosis.

\section{Cardiac anomalies}

EXIT procedure has been well established in cases of airway obstruction ${ }^{15}$; however, the safety of the procedure for fetuses with cardiac disease is unknown ${ }^{18}$. Three cases are presented in the literature with just one of the babies surviving to time of reporting. The use of EXIT in cardiac patients is risky due to the potential of fetal bradycardia from inhalational anaesthetic agents ${ }^{15}$.

Cuneo et al. $1 .^{15}$ recognise that when complete atrioventricular block (CAVB) presents prior to 20 weeks gestation, with ventricular rates of less than 55 beats per minute, cardiac dysfunction or hydrops, the fetus is at a high risk of death. These babies need to be paced immediately after birth and even then some may not survive ${ }^{15}$. Cuneo et al. ${ }^{15}$ were the first to report the use of EXIT to establish ventricular pacing. They inserted temporary epicardial pacing wires during the procedure and three days later permanent pacing leads were inserted. The baby was doing well at six months of age.

Asai et al. ${ }^{18}$ performed EXIT-to-ECMO in their patient with Collet-Edwards type II with truncal valve stenosis. They recognised, however, that without truncal valve repair the ECMO would be difficult to maintain, therefore following establishment of the ECMO circuit the neonate was delivered and transferred to another operating room where truncal valve repair surgery was completed. Although able to be weaned off ECMO, the patient developed an infection and died on day 24. Despite this outcome, Asai et al. ${ }^{18}$ maintain that with further improvements, EXIT-toECMO-to-surgery is a viable option in cardiac cases.

Said et al.7 also describes an EXITto-surgery case where the fetus suffered from hypoplastic left heart syndrome and intact atrial septum. ECMO was not an option in this case, so surgeons performed surgical atrial septectomy while maintaining fetal placental circulation. Post-operative complications led to the neonate requiring emergency ECMO in the NICU but unfortunately they died on day nine.

\section{Extremely low birth weight}

Hung et al. ${ }^{16}$ explain that neonates with extremely low birth weight are very difficult to intubate and quickly deteriorate when attempts fail. They described EXIT procedures in two patients, one with a single fetus and one with twins, who were likely to have preterm labour. All three 
patients underwent what appear to be modified EXIT procedures, as the authors refer to delayed cord clamping as their strategy and the fetuses were all fully delivered onto a working area above the mother's legs for easy intubation. Hung et al..$^{16}$ identify this method as having risks such as hypothermia, shorter umbilical cord in ELBW fetus, logistical issues with the working area and potential for dislodging the endotracheal tube on transfer.

\section{Micrognathia}

Duek et al. ${ }^{4}$ also described a modified EXIT procedure using delayed cord clamping for a fetus with Pierre Robin sequence and severe micrognathia. Intubation is challenging in patients with micrognathia as the larynx is located under the base of the tongue ${ }^{4}$. Additionally, Duek et al. ${ }^{4}$ reported breech presentation, bicornuate uterus, placenta located fundal posterior, low uterine segment dehiscence and umbilical cord entanglement as factors in their case preventing a traditional EXIT procedure. The fetus was delivered and with fetal-placental circulation still maintained a laryngoscopy attempt was made. This was unsuccessful therefore a tracheostomy was performed. Braden et al. ${ }^{2}$ also reported an inability to intubate utilising direct laryngoscopy and glidescope video laryngoscopy in a fetus with micrognathia; however, they were able to intubate the trachea with the use of a rigid bronchoscope.

\section{Congenital diaphragmatic hernia}

Despite being the original indication for EXIT procedure, congenital diaphragmatic hernia $(\mathrm{CDH})$ is the least common indication in this review with just one case identified in the literature search. Pucher et al. ${ }^{3}$ state that $\mathrm{CDH}$ occurs in one of every 2500-5000 births. The mortality rate is approximately 20 per cent with the degree of pulmonary hypoplasia being a key factor in survival. The fetus had a balloon inserted to occlude the trachea at 26 weeks and an emergency EXIT due to cardiac issues at 32 weeks to remove it ${ }^{3}$. In the case presented, lung hypoplasia was severe and despite a successful EXIT procedure, the neonate died on day two.

\section{Implications for perioperative nursing}

This review has highlighted the large number of EXIT procedure case studies published; however, there are no studies from an Australian context and limited discussion of the perioperative nurses' roles. Due to the nature of the procedure it does not lend itself to randomised controlled trials; nevertheless, there is scope to conduct qualitative studies. The studies reviewed in this paper, come from a variety of countries and describe similar strategies; however, it would be beneficial to identify procedural considerations from an Australian perspective.

In most of the cases reviewed the perioperative nurse role is not mentioned and is not explored at all despite core perioperative nursing tasks, such as ensuring all equipment is in good working order ${ }^{6}$, being discussed in the reports. The ethics and parental support of EXIT procedure has not been discussed as it is out of scope of this review; however, as a core nursing skill, this may be an area of future exploration from a perioperative nurse perspective. Recognition of the perioperative nurse as an important member of the multidisciplinary team can be achieved through ensuring knowledge translation from this review.

\section{Knowledge translation}

Perioperative nurses are an integral part of the multidisciplinary team required for EXIT procedure. These rare and highly specialised cases require specialist knowledge and skills to ensure the best possible outcomes for both the mother and baby. Perioperative nurses must understand the indications for the procedure, the expected outcomes and alternative plans if the initial course of action is unsuccessful. The perioperative nurse is expected to:

- ensure all specialist equipment is prepared and in good working order prior to a simulation of the procedure

- participate in the simulation of the procedure, communicating effectively with all members of the multidisciplinary team

- support the mother throughout the pre-, intra- and post-operative phases of the procedure

- ensure each medical team has dedicated nursing staff able to anticipate the needs of the anaesthetists and surgeons during the procedure

- educate their colleagues about the indications and procedural considerations of EXIT procedure.

\section{Conclusion}

This review has recognised EXIT procedure is being employed for an increasing number of conditions, with major developments occurring since it was first described for congenital diaphragmatic hernia. The treatment options within the procedure are also increasing, with ventricular pacing and cardiac surgery being described in these case studies for the first time. The cases reviewed here took place in a number of countries; however, all describe similar surgical and anaesthetic considerations. 
Administration of a general anaesthetic, ensuring tocolysis, partial delivery of the fetus and airway establishment in accordance with an airway algorithm and ECMO or resection are consistent across the reports. The role of the perioperative nurse within EXIT procedure needs to be further explored and can achieve recognition through development of specialist knowledge and skills in this procedure.

\section{Acknowledgement}

This work was submitted to the University of Tasmania as a partial requirement in master's degree subject CNA803. The author would like to acknowledge Dr Paula Foran, unit co-ordinator and tutor, for her encouragement and direction in writing this review.

\section{References}

1. Byun S, Lee S, Hong S, Ryu T, Kim B, Jung J. Use of GlideScope video laryngoscope for intubating during ex utero intrapartum treatment in a fetus with a giant cyst of the $4^{\text {th }}$ branchial cleft. Medicine 2016;95(39):1-4.

2. Braden A, Maani C, Nagy C. Anesthetic management of an ex utero intrapartum treatment procedure: A novel balanced approach. J Clin Anesth 2016;31:60-63.

3. Pucher B, Szydlowski J, Jonczyk-Potoczna K, Sroczynski ). The EXIT (ex utero intrapartum treatment) procedure - from the paediatric ENT perspective. Acta Otorhinolaringol Ital 2018;38:480-484.

4. Duek I, Gil Z, Solt I. Modified ex utero intrapartum treatment procedure in a bicornuate uterus breech presentation Pierre Robin fetus with severe micrognathia and cleft palate. Clin Case Rep 2018;6:20402044.
5. Matte G, Connor K, Toutenel N, Gottlieb D, Fynn-Thompson F. A modified EXIT-to ECMO with optional reservoir circuit for use during and EXIT procedure requiring thoracic surgery. J Extra Corpor Technol 2016;48(1):35-38.

6. Gonzales S, Goudy S, Prickett K, Ellis J. EXIT (ex utero intrapartum treatment) in a growth restricted fetus with tracheal atresia. Int J Pediatr Otorhinolaryngol 2018;105:72-74.

7. Kornacki J, Szydlowski J, Skrzyoczak J, Szczepanska M, Rajewski M, Koziolek A et al. Use of ex utero intrapartum treatment in fetal neck and high airway anomalies report of four clinical cases. J Matern Fetal Neonatal Med 2019;32(5):870-874.

8. Rodriguez M, Moreno-Cid M, Pascual A, Rubio A, Lopez M, Monux A et al. Delivery strategy for fetuses with cervical mass: The EXIT procedure. J Obstet Gynaecol 2016;36(1):64-65.

9. Brodsky J, Irace A, Didas A, Watters K, Estroff J, Barnewolt $C$ et al. Teratoma of the head and neck: A 41-year experience. Int J Paediatr Otorhinolaryngol 2017;97:66-71.

10. Whittemore ER, Knafl $K$. The integrative review: Updated methodology. J Adv Nurs 2005;52:546-553

11. Hochwald O, Gil Z, Gordin A, Winer Z, Avrahami R, Abargel E et al. Three-step management of a newborn with a giant, highly vascularised, cervical teratoma: $A$ case report. J Med Case Rep 2019;13(73):1-5.

12. Subramanian R, Mishra P, Subramanian $R$, Bansal S. Role of anaesthesiologist in ex utero intrapartum treatment procedure: a case review and review of anaesthetic management. J Anaesthesiol Clin Pharmacol 2018;34(2):148-154.

13. Lee J, Lee M, Kim Y, Shim J, Won H, Jeong E et al. Ex utero intrapartum treatment procedure in two fetuses with airway obstruction. Obstet Gynaecol Sci 2018;61(3):417-420.

14. Shamshirsaz A, Stewart K, Erfani H, Nassr A, Sundgren N, Mehollin-Ray A et al. Cervical lymphatic malformations. Prenatal diagnosis 2019;39(4):287-292.
15. Cuneo B, Mitchell M, Marwan A, Green M, Alvensleben J, Reynolds R et al. Ex utero intrapartum treatment to ventricular pacing: A novel delivery strategy for complete atrioventricular block with severe bradycardia. Fetal Diagn Ther 2017;42(4):311314.

16. Hung T, Huang T, Hsieh T. Ex utero intrapartum treatment for extremely low birthweight neonates requiring resuscitation at birth. Taiwan J Obstet Gynaecol 2017;56(4):561-563.

17. Said S, Qureshi M, Taggart N, Anderson H, O'Leary P, Cetta F et al. Innovative twostep management strategy utilising EXIT procedure for a fetus with hypoplastic left heart syndrome and intact atrial septum. Mayo Clin Proc 2019;94(2):356-361.

18. Asai H, Tachibana T, Shingu Y, Matsui Y. Ex utero intrapartum treatment-toextracorporeal membrane oxygenation followed by cardiac operation for truncus arteriosus communis. Interact Cardiovasc Thorac Surg 2018;26(2):353-354.

19. Agarwal A, Rosenkranz E, Yasin S, Swaminathan S. EXIT procedure for fetal mediastinal teratoma with large pericardial effusion: a case report with review of the literature. J Matern Fetal Neonatal Med 2018;31(8):1099-1103.

20. Olivares E, Castellow J, Khan J, Grasso S, Fong $\mathrm{V}$. Massive fetal cervical teratoma managed with ex utero intrapartum treatment (EXIT) procedure. Radiol Case Rep 2018;13(2):389-391.

21. Burwick R, Pilliod R, Dukhovny S, Caughey A. Fetal hydrops and the risk of severe preeclamsia. J Matern Fetal Neonatal Med 2019;32(6):961-965.

22. Mari G, Norton M, Stone J, Berghella V, Sciscione A, Tate D et al. Evaluation and management of polyhydramnios. Contemp Ob Gyn 2018;63(11);24-26. 